\title{
Acute toxicity assessment of Osthol content in bio-pesticides using two aquatic organisms
}

\author{
Eun-Chae Yim ${ }^{1}$, Hyeon Joe Kim², Seong-Jun Kim² \\ ${ }^{1}$ Interdisciplinary Program of Bioenergy and Biomaterial, Chonnam National University, Gwangju; ${ }^{2}$ Department of \\ Environment \& Energy Engineering, Chonnam National University, Gwangju, Korea
}

\begin{abstract}
Objectives This study focused on the assessment of acute toxicity caused by Osthol, a major component of environment-friendly biological pesticides, by using two aquatic organisms.

Methods The assessment of acute toxicity caused by Osthol was conducted in Daphnia magna and by examining the morphological abnormalities in Danio rerio embryos.

Results The median effective concentration value of Osthol in D. magna 48 hours after inoculation was $19.3 \mu \mathrm{M}$. The median lethal concentration of $D$. rerio embryo at 96 hours was $30.6 \mu \mathrm{M}$. No observed effect concentration and predicted no effect concentration values of Osthol in D. magna and D. rerio were calculated as 5.4 and $0.19 \mu \mathrm{M}$, respectively. There was an increase in the morphological abnormalities in $D$. rerio embryo due to Osthol over time. Coagulation, delayed hatching, yolk sac edema, pericardial edema, and pigmentation were observed in embryos at $24-48$ hours. Symptoms of scoliosis and head edema occurred after 72 hours. In addition, bent tails, ocular defects, and symptoms of collapse were observed in fertilized embryo tissue within 96 hours. Ocular defects and pigmentation were the additional symptoms observed in this study. Conclusions Because Osthol showed considerable toxicity levels continuous toxicity evaluation in agro-ecosystems is necessary when bio-pesticides containing Osthol are used.
\end{abstract}

Keywords Aute toxicity, Bio-pesticides, Danio rerio embryo, Daphnia magna, Osthol

\author{
Correspondence: \\ Seong-Jun Kim, PhD \\ 77 Youngbong-ro, Buk-gu, \\ Gwangju 500-757, Korea \\ Tel: +82-62-530-1864 \\ Fax: + 82-62-530-0864 \\ E-mail: seongjun@jnu.ac.kr
}

Received: July 29, 2014

Accepted: December 1, 2014

Published online: December 10, 2014

This article is available from: http://e-eht.org/

\section{Introduction}

The wide use of agricultural pesticides to increase farm products has created serious problems throughout the world, such as environmental destruction and degradation of ecosystems. Agricultural pesticides directly affect soil microbes and enzymatic activities, thereby leading to negative impacts on the $\mathrm{pH}, \mathrm{Eh}$, and nitrogen metabolism in soil [1].

In recent years, Organization for Economic Cooperation and Development (OECD) countries including South Korea have begun to take an interest in eco-friendly agricultural policies and well-being. Accordingly, the study and development of bio-pesticides for eco-friendly agriculture has become a priority. Biopesticides contain to biologically active substances to prevent various diseases and repel harmful insects or their commercialized biological products sold in markets.

According to the Korea Rural Economic Institute [2], the biopesticide market will amount to 3 trillion 873.2 billion sales in 2015, when agricultural pesticides with low pesticide certification system will be abolished, if some of them are replaced with pesticide-free products or organic products. It will increase to 7 trillion 474.9 billion sales in 2020 , which is $20 \%$ of the entire farm product market. While agricultural pesticides take 7-10 years to develop, bio-pesticides take around 3 years, and development costs are lower than those for agricultural pesticides.

However, there are disadvantages in the use of bio-pesticides. Their effect appears late, short-lived, and diminishes when they are not used at the right time. Furthermore, these products are costly. 

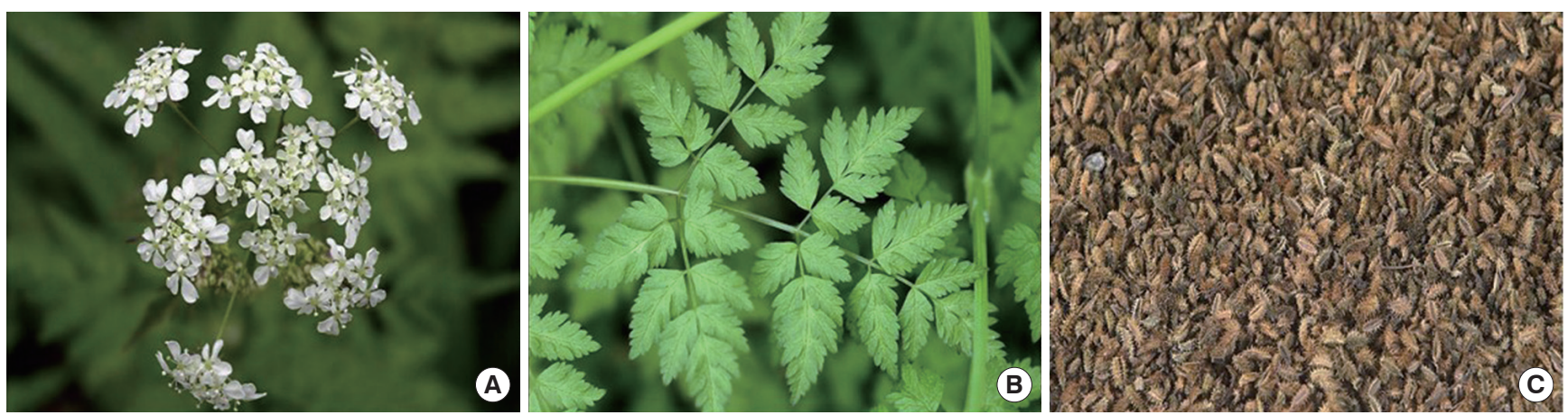

Figure 1. Images of flowers, leaves and fruit of Torilis japonica Decandolle (from left to right).

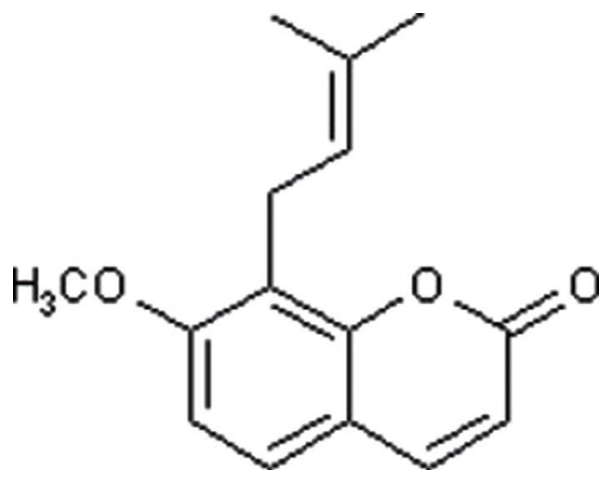

Figure 2. Chemical structure of Osthol.

Nevertheless, the study and development of bio-pesticides a must continue due to their eco-friendliness, lack of chemical-resistance, insurance of safe agricultural production, and usage of natural resources as well as promotion of safe eco-systems. To comply with the current need, a bio-pesticide (product name: SSGRI), which contains a mixture of Camphor and Osthol as the main ingredients, was developed.

Hedge parsley, called Torilis japonicas, is a plant that contains a large amount of Osthol and grows in South Korea, Taiwan, China, Ussuri River, Africa, Kavkaz, and Europe. It grows in grassland to heights of $30-70 \mathrm{~cm}$. Its fresh sprout is an edible vegetable and its fruit is used as an astringent, having anti-inflammatory and pesticidal properties (Figure 1). The main ingredients of its leaf include pinene, camphene, bornyl isovalerate, iso-borneol, and Osthol. In addition, Osthol is known to be effective in the treatment of pruritus genitalium, vulvar tumors, and postnatal dyslochia, as well as in the promotion of vitality [3-5].

In a previous study, our research team assessed the effects of acute exposure to Camphor [6]. In the present study, we review the effects of acute toxicity of Osthol using two aqua-organisms. Acute toxicity will be assessed using water flea fatality, swimminginhibition acute toxicity (median effective concentration $\left[\mathrm{EC}_{50}\right]$ ), and fry fatality (median lethal concentration $\left[\mathrm{LC}_{50}\right]$ ) of Danio rerio, and the morphological abnormalities induced by bio-pesti- cides on $D$. rerio embryo will be investigated. In addition, the impacts of toxicity will be compared, No observed effect concentration (NOEC) and predicted no effect concentration (PNEC) [7] will be drawn, and a stable concentration range for use on farmland eco-systems will be proposed through the assessment of acute toxicity on two organisms.

\section{Materials and Methods}

\section{Structure and Physiochemical Characteristics of Osthol}

Osthol (Santa Cruz Biotechnology, Dallas, TX, USA; GC level), extracted from Cnidii Fructus, Torilis Fructus, has a molecular weight (MW) of 244.29, octanol-water partition coefficient of 3.45 , and a low water solubility but high solubility in ethanol. The structure is shown in Figure 2. The concentration of Osthol reagent used in the present research is $\geq 98.0 \%$.

\section{Rearing Conditions of Target Species for Toxicity Assessment}

\section{D. magna}

D. magna was distributed from a chemical toxicity research institute and was cultured in accordance with OECD guideline 202 methods [8]. The rearing condition was set to $\mathrm{pH} 7.5 \pm 0.2$, temperature of $20 \pm 1^{\circ} \mathrm{C}$ and photoperiod of 16:8-hour light/ dark (L/D). For food, $7-10 \times 10^{7}$ cells/ $\mathrm{L}$ of Chlorella vulgaris was provided every day. Rearing water was changed three times a week, and the number of female parents was set to 10/L.

\section{D. rerio}

The $D$. rerio used in acute fish toxicity assessment was distributed from Kyungpook National University. Rearing conditions were set to a temperature of $28 \pm 1^{\circ} \mathrm{C}$ and photoperiod of 16:8-hour $\mathrm{L} / \mathrm{D}$; rearing water was dissolved with $0.065 \mathrm{~g} / \mathrm{L}$ of sodium bicarbonate (Dae Jung Chemicals, Siheung, Korea; extra pure lev- 
el), and the $\mathrm{pH}$ was set to $\mathrm{pH} 7.5 \pm 0.2$ with $12 \%$ sodium phosphate monobasic anhydrous (Dae Jung Chemicals; extra pure level) solution, while the conductivity was set to $0.39-0.43 \mathrm{mS} /$ $\mathrm{cm}$ with $0.16 \mathrm{~g} / \mathrm{L}$ of sea salt (Aquarium Systems, France). As for food small tropical fish feed (Guppy BOb; Jeil Feed, Daejeon, Korea) was provided 3 times a day, and Ocean Star International Brine Shrimp (Snowville, UT, USA) was provided once a week.

\section{Toxicity Assessment Method}

\section{Preparation of toxicity substance}

For the toxicity assessment, Osthol (MW: 244.29; 98.0\%), GC grade reagent was purchased from Santa Cruz Biotechnology (GC level). As a solvent for Osthol, ethanol (Junsei Chemicals; extra pure level) was used. Osthol $0.25 \mathrm{~g}$ was dissolved in ethanol, and diluted to obtain a $50 \mathrm{~mL}$ stock solution of $0.02 \mathrm{M}$. To adjust the concentration for each evaluation, the stock solution was diluted with culturing seawater. When dissolved, Osthol becomes alkaline. For this reason, we adjusted all solutions to $\mathrm{pH}$ $7.5 \pm 0.2$ (the same as that of control group) at all concentrations.

\section{Acute Toxicity Assessment of D. magna}

The individuals D. magna used in the test were young, healthy individuals aged less than 24 hours. Osthol were prepared in beakers at concentrations of $2.5,5.0,10.0,20.0$, and $40.0 \mu \mathrm{M}$; $10 \mathrm{D}$. magna were placed in each beaker. During the experimental period, oxygen and food were not provided. Also, death and immobilization were observed between 24 and 48 hours. All experiments were repeated three times, and SigmaPlot version 12.0 (Systat Software, Chicago, IL, USA) was used for statistical evaluations. The $\mathrm{pH}$ of the $40.0 \mu \mathrm{M}$ Osthol solution was 0.4 higher than that of the control group; hence, we adjusted all concentrations to $\mathrm{pH} 7.5 \pm 0.2$ to match the control.

\section{Egg Production of D. rerio}

During spawning, male and female $D$. rerio are easily distinguishable, because male $D$. rerio have an orange body with a silver belt whereas female $D$. rerio have a red body and swollen abdomen.

The night before the spawning, male and female $D$. rerio in a 2:1 ratio were transferred to the darkened mating cage. During the copulation, spawning, and fertilization, light was emitted and eggs were produced within 30 minutes. $D$. rerio tends to eat their eggs; hence, and the adults were separated from the eggs [9]. The collected eggs were washed with methylene blue solution and egg water. The fertilized and unfertilized eggs were separated using an optical microscope (Eclipse E200; Nikon, Tokyo, Japan), and only the fertilized eggs were used for further observations.

\section{Acute toxicity Assessment and Embryo Toxicity Assessment of $D$. rerio}

Osthol was prepared in $2.5,5.0,10.0,20.0$, and $40.0 \mu \mathrm{M}$ concentrations by diluting with the $D$. rerio rearing water. Then, 2.5 $\mathrm{mL}$ of Camphor was put in each concentration in 24-well plates, and three sets of experiments were repeated 10 times. During the test, the temperature was set to $28 \pm 1^{\circ} \mathrm{C}$, $\mathrm{pH}$ was set to $7.5 \pm 0.2$, conductivity was set to $0.4 \mathrm{mS} / \mathrm{cm}$, and photoperiod was set to 16/8-hour L/D. Individuals that died or showed morphological abnormalities were observed with a microscope and numbered within 0-96 hours, for every 24 hour, and statistical analyses were carried out through SigmaPlot version 12.0 Embryo toxicity was assessed with 30 replicates per concentration, and the incidents of every abnormality were cumulatively recorded and expressed as a percentage. As there were cases where multiple incidents occurred for a single embryo, the total amount could be over $100 \%$.

\section{Estimation of No Observed Effect Concentration and Predicted No Effect Concentration}

If only limited toxicity data were obtained from the toxicity assessment of chemical substances in the OECD, a constant assessment factor was used in each extrapolation stage to predict the PNEC of the ecosystem. The acute toxicity assessment results for the two species of subject organisms were adjusted to a constant assessment factor of 100 to derive the PNEC and NOEC $[7,10]$.

\section{Results}

\section{Acute Toxicity Assessment of D. magna}

D. magna were not affected by toxicity below $5.0 \mu \mathrm{M}$ after 48 hours; however, at $10.0 \mu \mathrm{M}$ Osthol led to fatalities and inhibited swimming. At the highest concentration of $40.0 \mu \mathrm{M}$, the survival rate was $6.7 \%$, exhibiting very high toxicity. In this assessment, in which the impact of solvent was excluded, the survival rate in $0.188 \%$ ethanol was $90.0 \%$, showing almost no toxicity. Meanwhile, the $\mathrm{EC}_{50}$ of D. magna after 48 hours was $19.3 \mu \mathrm{M}$ (Figure 3A). 


\section{Egg Production of $D$. rerio}

Osthol was toxic to $D$. rerio embryos and increased the fatality rate at concentrations above $5.0 \mu \mathrm{M}$. The amount of ethanol contained in Osthol $40.0 \mu \mathrm{M}$ was $0.188 \%$. The toxic effect of the solvent on fertilized $D$. rerio eggs did not appear as it did in $D$. magna. LC $_{50}$ value of Osthol's exposure to $D$. rerio embryo for 96 hours was $30.6 \mu \mathrm{M}$ (Figure 3B).

\section{Effects of Elapsed Time on Fertilized Eggs of D. rerio}

\section{Twenty-four Hours after Fertilization}

When Osthol at concentration of 5-40 $\mu \mathrm{M}$ was prepared and exposed to D. rerio, 24 hours after fertilization, congelation (C) of 10.0, 10.0, and 53.3\% occurred at 10.0, 20.0, and $40.0 \mu \mathrm{M}$, respectively. However, $\mathrm{C}$ did not occur at concentrations below 5.0 $\mu \mathrm{M}$. Morphological abnormalities of $D$. rerio 24 hours after fertilization are shown in Figure 4 and Table 1. It is important to note that congelation at $40.0 \mu \mathrm{M}$ was 5.3-fold higher than at 20.0 $\mu \mathrm{M}$, showing a significant increase. A mechanism that promoted
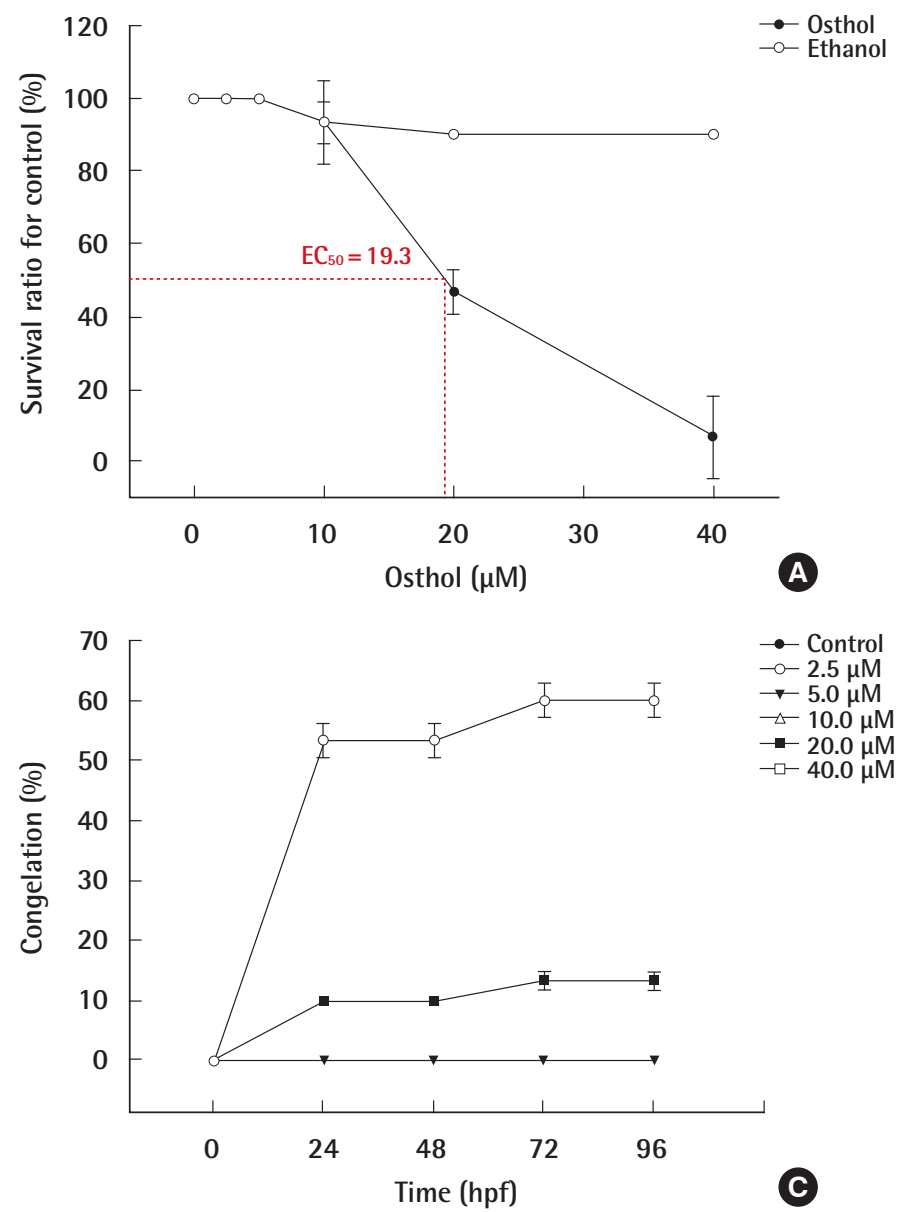

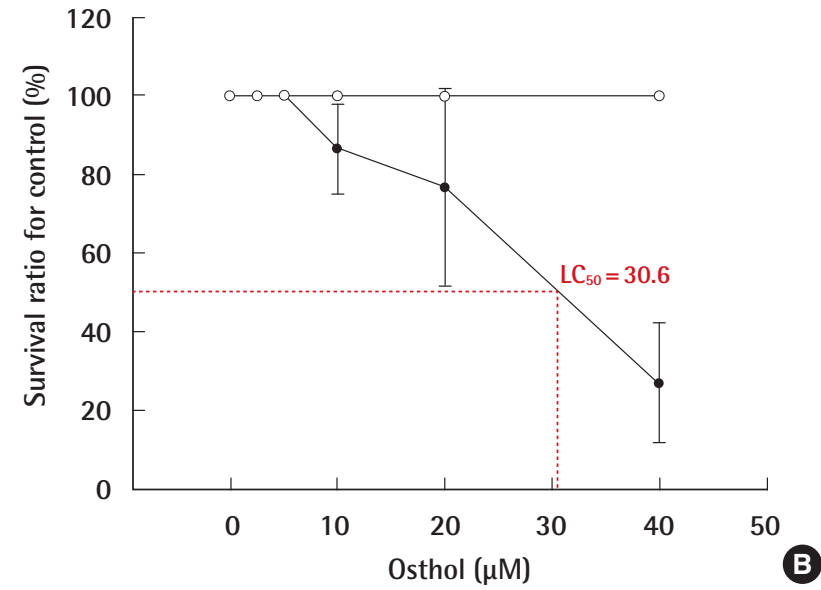

significant $\mathrm{C}$ emerged above certain concentrations (Figure 3C).

\section{Forty-eight Hours after Fertilization}

Forty-eight hours after fertilization, $10 \% \mathrm{C}$ occurred at 10.0 $\mu \mathrm{M}, 10 \% \mathrm{C}$ and $3.3 \%$ tail edema (TE) at $20.0 \mu \mathrm{M}$, and $53.3 \% \mathrm{C}$ and $6.7 \% \mathrm{TE}$ at $40.0 \mu \mathrm{M}$. The morphological abnormalities of D. rerio, 48 hours after fertilization, are shown in Figure 4 and Table 1.

\section{Seventy-two Hours after Fertilization}

Seventy-two hours after fertilization, there appeared C: $13.3 \%$ at $10.0 \mu \mathrm{M}, \mathrm{C} 13.3 \%$, pericardial edema (PE) 33.3\% and TE $36.7 \%$ at $20.0 \mu \mathrm{M}$, and C $60.0 \%$, yolk sac edema (YSE) $10.0 \%$, PE 50.0\%, TE 36.7\%, Head edema (HE) 3.3\% and bent spine (BS) $3.3 \%$ at $40.0 \mu \mathrm{M}$. The morphological abnormalities of $D$. rerio, 72 hours after fertilization, are shown in Figure 4 and Table 1.

\section{Ninety-six Hours after Fertilization}

Ninety-six hours after fertilization, C, PE and TE at 10.0 and $20.0 \mu \mathrm{M}$ remained constant at the level observed at 72 hours, with

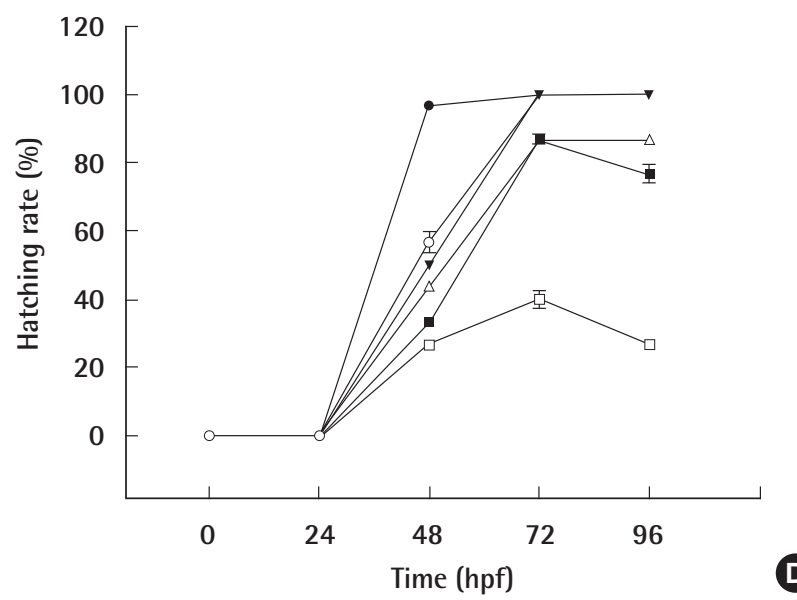

Figure 3. Acute toxicity of Osthol to D. magna (A) and D. rerio embryo (B) at 96 hours and the congelation for each observation time by Osthol (C), hatching rate for each observation time by Osthol (D), $(n=30)$. EC $C_{50}$, median effective concentration; $L C_{50}$, median lethal concentration. 


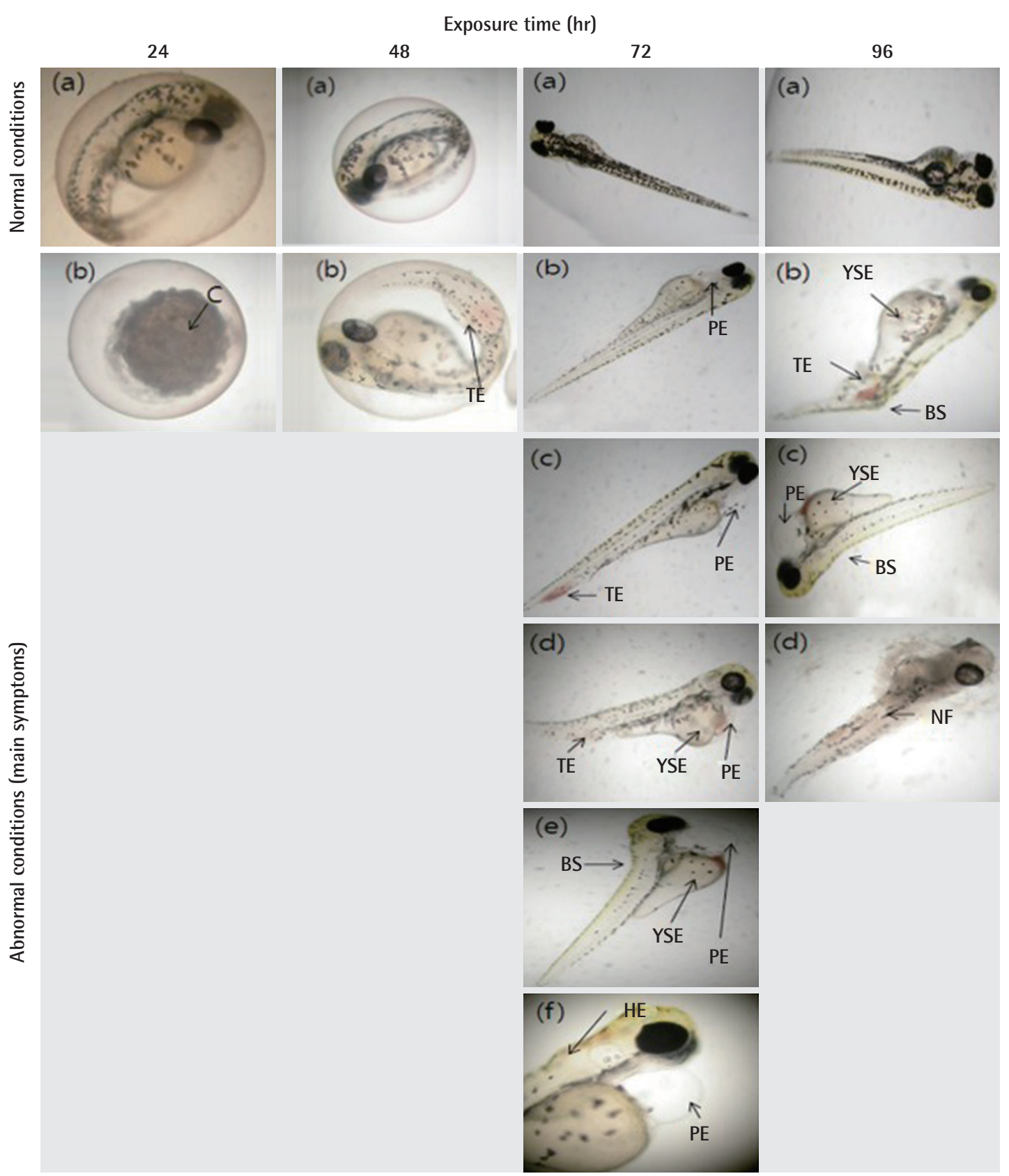

Figure 4. Image summary of morphological abnormalities of $D$. rerio embryo by Osthol. C, congelation; YSE, yolk sac edema; PE, pericardiac edema; TE, tail edema; BS, bent spine; HE, head edema; NF, collapse symptoms of fertilized embryo tissue.

no morphological abnormalities observed at increasing concentrations. Morphological abnormalities other than TE, bent spine (BS), and collapse of fertilized egg tissue (NF) at $40.0 \mu \mathrm{M}$ was consistent with those observed 72 hours after fertilization. However, bent tail (BT), BS, and NF were 40.0, 13.3, and 13.3\%, respectively, which were greater than those at 72 hours post fertilization (Figure 5). The morphological abnormalities of $D$. rerio, 96 hours after fertilization, are shown in Figure 4 and Table 1.

\section{Morphological Abnormality Changes with Concentration and Time}

Osthol was prepared at various concentrations and the types of abnormalities present 96 hours after fertilization were observed. No morphological abnormalities were found below 5.0 $\mu \mathrm{M}$. However, $13.3 \% \mathrm{C}$ occurred at $10.0 \mu \mathrm{M}$ concentration; C, $\mathrm{PE}$ and TE occurred in 13.3, 33.3, and $36.7 \%$ of cases, respectively, at $20.0 \mu \mathrm{M}$; and C, YSE, PE, TE, HE, BT, and abnormalities where the form of the fertilized egg tissue showed symptoms of NF occurred at 60.0, 10.0, 50.0, 40.0, 3.3, 13.3, and 13.3\%, re- 


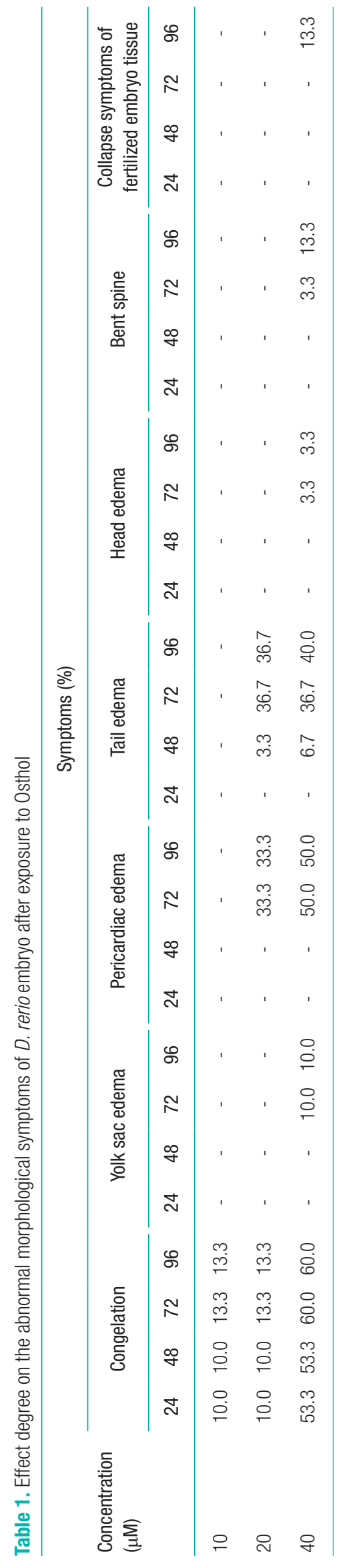

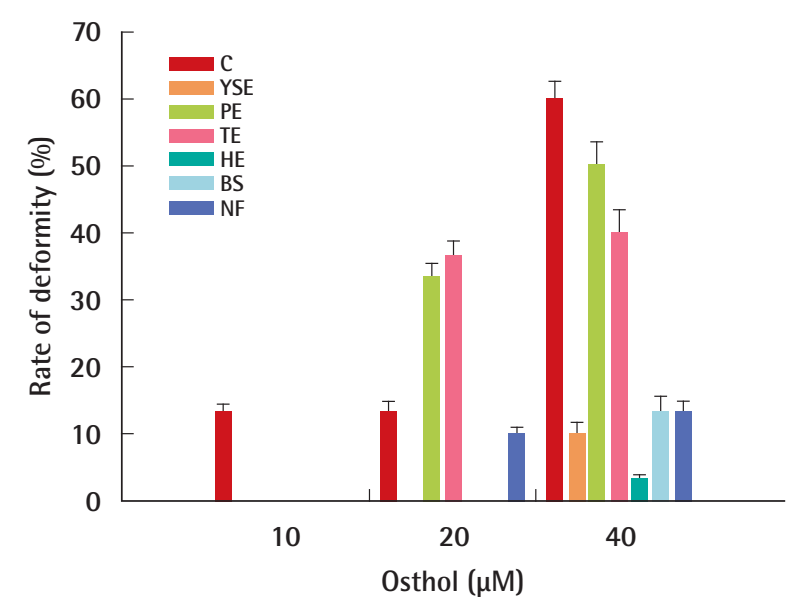

Figure 5. Rate of congelation (C), yolk sac edema (YSE), pericardiac edema $(\mathrm{PE})$, tail edema (TE), head edema (HE), bent spine (BS) and collapse symptoms of fertilized embryo tissue (NF) caused by Osthol at 96 hours $(n=30)$.

spectively, at $40.0 \mu \mathrm{M}$ (Figure 4 and Table 1).

Edema accompanied by hemorrhage was observed as a morphological abnormality. According to a previous study reported by Ko et al. [11], Osthol lowers blood pressure by dilating the thoracic aorta in rat, leading to a decrease in systolic blood pressure. In our study, it is thought that there was expansion and destruction of immature vessels in the emerging process of fertilized $D$. rerio eggs, thereby resulting in bleeding accompanied by edema. Although the reason was not clear, certain toxicity was observed to occur, which destroyed the vascular system in $D$. rerio and led to edema as a consequence of bleeding.

\section{Change in the Congelation Rate}

While $\mathrm{C}$ of fertilized $D$. rerio eggs by Osthol was not observed below $5.0 \mu \mathrm{M}$, it was increased at 10.0, 20.0, and $40.0 \mu \mathrm{M}$ up to 72 hours, and was then maintained a constant level until 96 hours (Figure 3C). Such fertilized eggs did not hatch and died.

Calcium $(\mathrm{Ca})$ has a main role in information transmission and controls various functions that are essential for sustaining life [12]. Division and multiplication of fertilized eggs occurs following the influx of $\mathrm{Ca}$, and an increase of $\mathrm{Ca}$ in cells can lead to death. Cell membranes have $\mathrm{Ca}$ channels that control the influx of Ca into cells, a Ca pump, which removes $\mathrm{Ca}$ from cells, and a $\mathrm{Ca}^{+} / \mathrm{Na}^{+}$exchange pump, which removes $\mathrm{Ca}$ by exchanging it with $\mathrm{Na}$, and thereby maintaining intracellular $\mathrm{Ca}$ at a constant level.

Chiou et al. [13] reported the inhibitory effect of Osthol on the influx of $\mathrm{Ca}$. $\mathrm{HE}$ confirmed that $\mathrm{C}$ occurred in $D$. rerio embryos at concentrations over $10.0 \mu \mathrm{M}$, in a manner that was not dependent on concentration. Although there is no clear conclusion for its reason, its possibility cannot be excluded. 
Table 2. The values of $\mathrm{EC}_{50}$ or $\mathrm{LC} \mathrm{C}_{50}$, NOEC and PNEC of Osthol obtained from the acute toxic assessment using $D$. magna and $D$. rerio

\begin{tabular}{llllll}
\hline Ingredient & Species & $\begin{array}{c}\mathrm{E}(\mathrm{L}) \mathrm{C}_{50}(\mu \mathrm{M}) \\
(\text { dilution rate) }\end{array}$ & $\begin{array}{c}\text { NOEC }(\mu \mathrm{M}) \\
(\text { dilution rate) }\end{array}$ & Factor & $\begin{array}{c}\text { PNEC }(\mu \mathrm{M}) \\
(\text { dilution rate })\end{array}$ \\
\hline Osthol & D. magna & $19.3(\times 1,036)$ & $5.4(\times 3,704)$ & 100 & $0.19(\times 105,263)$ \\
& D. rerio & $30.6(\times 654)$ & $5.4(\times 3,704)$ & & \\
\hline
\end{tabular}

EC 50 , median effective concentration; $L_{50}$, median lethal concentration; NOEC, no observed effect concentration; PNEC, predicted no effect concentration.

\section{Change in Hatchability}

While the hatching rate of the control group was high at $96.7 \%$ after 48 hours fertilization, the hatching rates at 2.5, 5.0, 10.0, 20.0, and $40.0 \mu \mathrm{M}$ were 56.7, 50.0, 43.3, 33.3, and $26.7 \%$, respectively, showing that the hatching rate decreased with increasing concentration. However, the hatching rates at 2.5, 5.0, and $10.0 \mu \mathrm{M}$ were 100,100 , and $86.7 \%$, respectively, after 72 hours, and maintained until 96 hours after fertilization.

Considering that the normal hatching time of the control group was after 48 hours, the hatching time was delayed significantly. In addition, the hatching rates at 20.0 and $40.0 \mu \mathrm{M}$ after 72 hours were 86.7 and $40.0 \%$, respectively, which were lower than those at low concentrations. Hatching rates after 96 hours fell to 76.7 and $26.7 \%$, which were lower than those at 72 hours. The reason is that although they hatched after 72 hours, they subsequently died due to toxicity, thus resulting in an overall lower hatching rate (Figure 3D).

\section{Safe Application Concentration of Bio-pesticide}

This study conducted an acute toxicity assessment of Osthol using D. magna and D. rerio. According to the result, D. magna was more sensitive to the effects of toxicity than was $D$. rerio. The $\mathrm{EC}_{50}$ of D. magna at 48 hours of exposure was $19.3 \mu \mathrm{M}$, which corresponds to 1,036-fold when converting into the dilution magnification value of the bio-pesticide. This result means that the $\mathrm{EC}_{50}$ was 1,000-fold of the actual pesticide spraying concentration. Meanwhile, since the test was conducted on two organisms, an uncertainty evaluation factor of 100 was applied to the $\mathrm{EC}_{50}$ of water fleas, which showed sensitivity to toxicity, and then PNEC was drawn. PNEC at this point was predicted to be $0.19 \mu \mathrm{M}$ (105,263-fold diluted water).

In other words, when Osthol exists below $19 \mu \mathrm{M}$ in an ecosystem, toxicity cannot be predicted. In addition, since the NOEC value was assessed to be $5.4 \mu \mathrm{M}$ (3,704-fold), it can be said that no toxic effect was observed below this concentration. Accordingly, based on the results stated above, it can be concluded that a significant toxic effect may occur when sprayed on sites at 1,000-fold dilution (Table 2).

\section{Discussion}

The assessment of acute toxicity of Osthol to two organisms was conducted. As a result, the $\mathrm{EC}_{50}$ of its exposure to D. magna for 48 hours was $19.3 \mu \mathrm{M}$ (1,036-fold diluted water), and the $\mathrm{LC}_{50}$ of its exposure to D. rerio embryos for 96 hours was 30.6 $\mu \mathrm{M}$ (654-fold diluted water). NOEC and PNEC of Osthol were $5.4 \mu \mathrm{M}$ (3,704-fold diluted water), 0.19 $\mu \mathrm{M}$ (105,263-fold diluted water), respectively. At 48 hours, $C$, a morphological abnormality of $D$. rerio, increased at concentrations above 10.0 $\mu \mathrm{M}$, and was maintained for 72 hours.

$\mathrm{TE}$ was found in hatching-delayed embryo in concentrations above 20.0 $\mu \mathrm{M}$. Seventy-two hours after fertilization, PE, YSE, $\mathrm{HE}$, and BT abnormalities were discovered above $20.0 \mu \mathrm{M}$. Ninety-six hours after fertilization, abnormality manifest as NF appeared, and bleeding occurred together at the place where edema appeared. Since the $\mathrm{EC}_{50}$ of Osthol was $19.3 \mu \mathrm{M}$, and the site spraying concentration of 1,000-fold diluted water (20.0 $\mu \mathrm{M})$ are similar, it is predicted that significant toxic effects will appear at the sprayed sites. In our previous study, NOEC of Camphor was $55.2 \mu \mathrm{M}(7,156$-fold diluted water based on the guidelines on bio-pesticides), and PNEC was $3.95 \mu \mathrm{M}$ (100,000-fold diluted water).

Dilution magnifications corresponding to the $\mathrm{EC}_{50}$ were 1,000-fold when compared with the $\mathrm{EC}_{50}(395.0, \mu \mathrm{M})$ of Camphor and 1,000-fold of the dilution magnification value (395.0 $\mu \mathrm{M})$. However, when bio-pesticide SSAGRI was assessed using D. magna, it showed very high toxicity, causing $100 \%$ death at 500-fold diluted water and 1,000-fold diluted water, which are spraying standards. Main ingredients of SSAGRI include Camphor $6.25 \%$, Osthol $0.5 \%$, surfactant $5 \%$ and grapefruit seed extract $5 \%$. This indicates that the mixture of several ingredients can cause toxicity. To clarify this, further studies on the difference between each ingredient's toxicity and that of the mixture are required.

\section{Acknowledgements}

We sincerely thank the Ministry of Trade, Industry and Energy who supported the present research, as part of a Program Sponsoring the Leading Businesses in the Honam Economic Region (no. R0001955). 


\section{Conflict of Interest}

The authors have no conflicts of interest with material presented in this paper.

\section{References}

1. Lee KS. Evaluation on the effects of pesticide residues to agroecosystem in Korea. Korean J Environ Aagric 1997;16(1):80-93 (Korean).

2. Jeong HK,Moon DH. Response strategy to the abolishment of low-pesticide agricultural product certification. Seoul: Korea Rural Economic Institute; 2013, p. 88 (Korean).

3. Matsuda H, Ido Y, Hirata A, Ino Y, Naruto S, Amamiya T, et al. Antipruritic effect of Cnidii Monnieri Fructus (fruits of Cnidium monnieri CUSSON). Biol Pharm Bull 2002;25(2):260-263.

4. Matsuda H, Tomohiro N, Ido Y, Kubo M. Anti-allergic effects of cnidii monnieri fructus (dried fruits of Cnidium monnieri) and its major component, osthol. Biol Pharm Bull 2002;25(6):809-812.

5. Yamahara J, Kozuka M, Sawada T, Fujimura H, Nakano K, Tomimatsu T, et al. Biologically active principles of crude drugs. Anti-allergic principles in "Cnidii monnieri". Chem Pharm Bull (Tokyo) 1985;33(4):1676-1680.

6. Yim EC, Kim HJ, Kim SJ. Acute toxicity assessment of camphor in biopesticides by using Daphnia magna and Danio rerio. Environ
Health Toxicol 2014;29:e2014008.

7. van Leeuwen CJ, Vermeire T. Risk assessment of chemicals: an introduction. 2nd ed. Dordrecht: Springer; 2007, p. 326-340.

8. Organization for Economic Cooperation and Development. Test No. 202: Daphnia sp. acute immobilisation test; 2004 [cited 2014 Jun 20]. Available from: http://www.oecd-ilibrary.org/docserver/ download/9720201e.pdf?expires=1417618460\&id=id\&accname =guest $\&$ checksum $=$ BD88013F235EB83D42D7764D3EF51C7E.

9. Lammer E, Carr GJ, Wendler K, Rawlings JM, Belanger SE, Braunbeck $\mathrm{T}$. Is the fish embryo toxicity test (FET) with the zebrafish (Danio rerio) a potential alternative for the fish acute toxicity test? Comp Biochem Physiol C Toxicol Pharmacol 2009;149(2):196209.

10. Yim EC, Shin JJ, Park IT, Han HK, Kim SW, Cho H, et al. Acute toxicity assessment of new algicide, thiazolidinedione derivative (TD53) to marine ecosystem. Korean Soc Biotechnol Bioeng J 2011;26(1):7-12 (Korean).

11. Ko FN, Wu TS, Liou MJ, Huang TF, Teng CM. Vasorelaxation of rat thoracic aorta caused by osthole isolated from Angelica pubescens. Eur J Pharmacol 1992;219(1):29-34.

12. Huzita T. Wonders of the new calcium: calcium to support the future of the human race. Tokyo: Kodansha; 1996, p. 208 (Japanese).

13. Chiou WF, Huang YL, Chen CF, Chen CC. Vasorelaxing effect of coumarins from Cnidium monnieri on rabbit corpus cavernosum. Planta Med 2001;67(3):282-284. 